\title{
OUTCOMES AFTER PCI IN PATIENTS WITH LV DYSFUNCTION
}

\author{
M Ravikiran, G. Indrani
}

\section{Abstract}

Background: Coronary artery disease (CAD) is the most common cause of left ventricular dysfunction. Percutaneous coronary intervention (PCI) in patient with LV dysfunction is a high risk procedure and may be associated with adverse outcomes. We observed for outcomes after PCI in the elective and acute coronary syndrome setting in patient with LV dysfunction.

Methods: A prospective single center study was performed in 836 patients with and without $L V$ dysfunction who underwent PCI with a follow up period of 1 year for MACCE.

Results: A total of 836 patients were studied. 329 (39.4\%) patients have LV dysfunction (LVD) and 507 (60.6\%) patients have good LV function (GLV). Among the patients with LVD, $160(48.6 \%)$ has mild, 89 (27.1\%) has moderate, 80 (24.3\%) has severe LVD. Mean age was $56.5 \pm 12.5$ years in patients with GLV and $58.8 \pm 10$ years in LVD patients $(p=0.003)$. Number of males were 259 (78.7\%) in LVD and 364 (71.7\%) in GLV group. Hypertension and diabetes were present in $237(72 \%)$ vs $368(72.5 \%), 168$ (51\%) vs 286 (56.4\%) in LVD and GLV groups respectively $(p=0.8,0.1)$. There was no difference in the previous history of CABG (5.2\% vs $3.4 \%, p=0.2)$ and PCI $(19.5 \%$ vs $16.4 \%, p=0.3)$ in both groups. 174 (52.9\%) patients with LVD and 409 (80.7\%) patients with GLV has chronic stable angina. Multivessel PCI was done in 79 (24\%) patients with LVD and $110(21.7 \%)$ patients with GLV ( $p=0.4)$. Major adverse cardiovascular and cerebrovascular events (MACCE) occurred in 3 patients with mild, 5 patients with moderate, 6 patients with severe LVD during the follow up of 1 year. There was no difference in outcomes between the LVD and GLV group at one year ( $p=0.2)$, but when a subgroup analysis was made among patients with $L V$ dysfunction there was a significant occurrence of MACCE in patients with severe LV dysfunction when compared with mild LVD ( $p=0.05)$.

Conclusion: There was no significant difference between the occurrence of MACCE in patients with LV dysfunction and without LV dysfunction who underwent PCI. But when a subgroup analysis was done there was a significant occurrence of MACCE in patients with severe LV dysfunction $(p=0.05)$ when compared to mild LVD.

Keywords: LV Dysfunction, PCI Outcome.

Article received on 1 APR 2017, published on 30 APR 2017.

Ravi Kiran.M ${ }^{1}$, G.Indrani

'Senior Resident, Department of Cardiology, NIMS, India.

${ }^{2}$ Ph.D Student, Department of Cardiology, NIMS, India.

Corresponding Author: Ravi Kiran. M

Email: ravikiran927@gmail.com

\section{INTRODUCTION:}

Between 10 and $30 \%$ of patients undergoing percutaneous coronary intervention (PCI) have left ventricular (LV) dysfunction [1-4] yet individuals with significant LV dysfunction are often excluded from contemporary randomized controlled trials [5,6]. Patients with LV dysfunction undergoing PCI tend to be older, with more co-morbid conditions such as renal failure and diabetes and have more extensive and complex disease than those with good LV function. $[7,8]$ The adverse demographic features commonly found in patients with impaired LV function are known to contribute to unfavorable outcomes following PCI and LV function features strongly as a predictor of adverse outcomes in contemporary risk stratification scores for patients undergoing PCI $[9,10]$. Previous studies have suggested that impaired LV function may predict mortality $[1,3,4,10]$ and major adverse cardiovascular events (MACE) outcomes [1,7] following PCI.

However, many of these studies that have specifically assessed the impact of LV function on outcomes following PCI have limited their observations to patients undergoing PCI in the elective setting $[1,8,11]$ and often only report the impact of LV dysfunction on in-hospital outcomes [8] with very few reporting outcomes beyond 1 year [3,4]. Furthermore, several previous reports studied the impact of LV function in patients who underwent PCI in the late 1990s and so the outcomes reported may not be applicable to contemporary cohorts $[1,8]$. In addition, the prognosis of patients with impaired ventricular function has been altered favorably over recent years because of better pharmacological and device therapies. More contemporary reports are based on cohorts from randomized controlled trials, hence may not be representative of real-world practice[3].

We report the association between LV function and the occurrence of MACCE in patients undergoing PCI in both the elective and acute coronary syndrome (ACS) setting. 


\section{METHODS:}

In the present study, a total of 836 patients who are admitted for PCI were included and they were followed on an outpatient basis for a period of 1 year. Patients with both chronic stable angina and acute coronary syndrome were included. Patients were divided into two groups those with good left ventricular function and those with left ventricular dysfunction. LV function was assessed by $2 \mathrm{D}$ echocardiography. Simpson's rule was used to calculate systolic and diastolic LV volumes.Patients with LV dysfunction were subclassified into mild, moderate and severe with an ejection fraction of $40-50 \%, 30-39 \%$ and $<30 \%$ respectively. Patients were observed for occurrence of major adverse cardiovascular and cerebrovascular events, including cardiovascular mortality, nonfatal myocardial infarction, cerebrovascular accidents and rehospitalisation for heart failure. Patients were followed on an outpatient basis over a period of 1 year.Baseline characteristics and clinical outcomes were presented as mean \pm standard deviation for continuous variables and as proportions for categorical variables. Statistical analysis was performed using Minitab version 17. Binary logistic analysis and chi square test were performed.

\section{RESULTS:}

A total of 836 patients were studied. 329 (39.4\%) patients has LV dysfunction (LVD) and 507 (60.6\%) patients has good LV function (GLV). Among the patients with LVD, $160(48.6 \%)$ has mild, $89(27.1 \%)$ has moderate, 80 (24.3\%) has severe LVD. Mean age was $56.5 \pm 12.5$ years in patients with GLV and $58.8 \pm 10$ years in LVD patients $(p=0.003)$. There was no significant difference between the two groups (Fig.1).

Fig.1: Age distribution curves

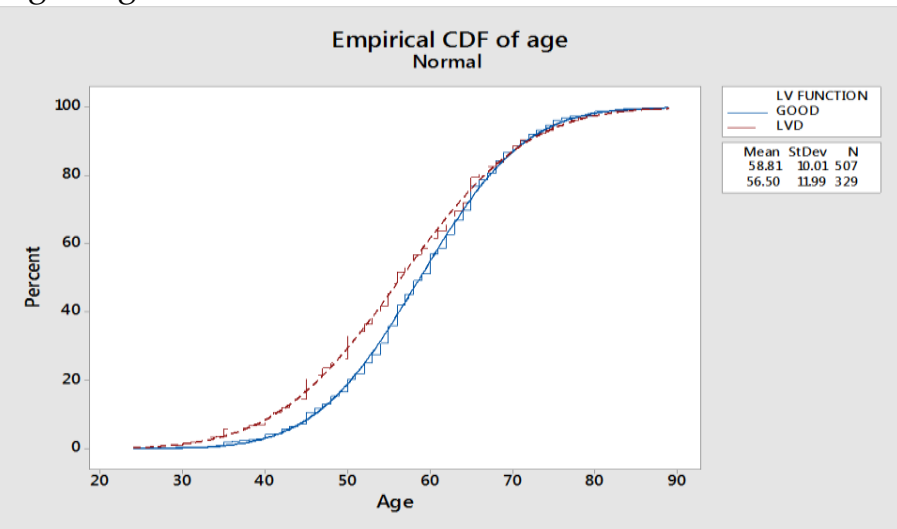

Number of males were $259(78.7 \%)$ in LVD and 364 $(71.7 \%)$ in GLV group (Fig.2).

Fig. 2: Sex distribution

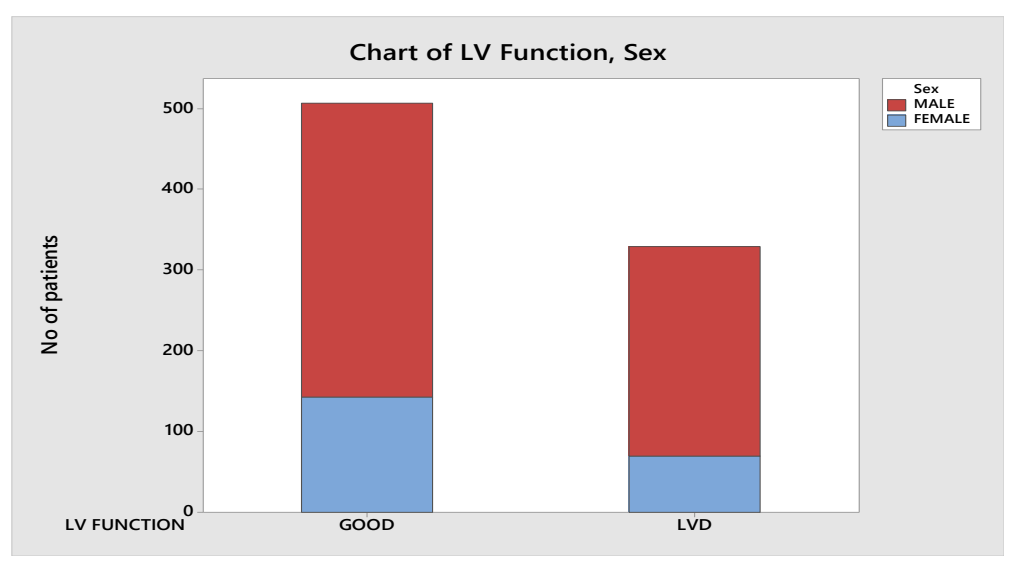

Hypertension and diabetes were present in $237(72 \%)$ vs $368(72.5 \%), 168(51 \%)$ vs 286 (56.4\%)in LVD and GLV groups respectively ( $\mathrm{p}=0.8,0.1)$. There was no difference in the previous history of CABG $(5.2 \%$ vs $3.4 \%, \mathrm{p}=0.2)$ and PCI $(19.5 \%$ vs $16.4 \%, \mathrm{p}=0.3)$ in both groups. 174 (52.9\%) patients with LVD and $409(80.7 \%)$ patients with GLV has chronic stable angina (Fig.3).

Fig.3: Type of CAD

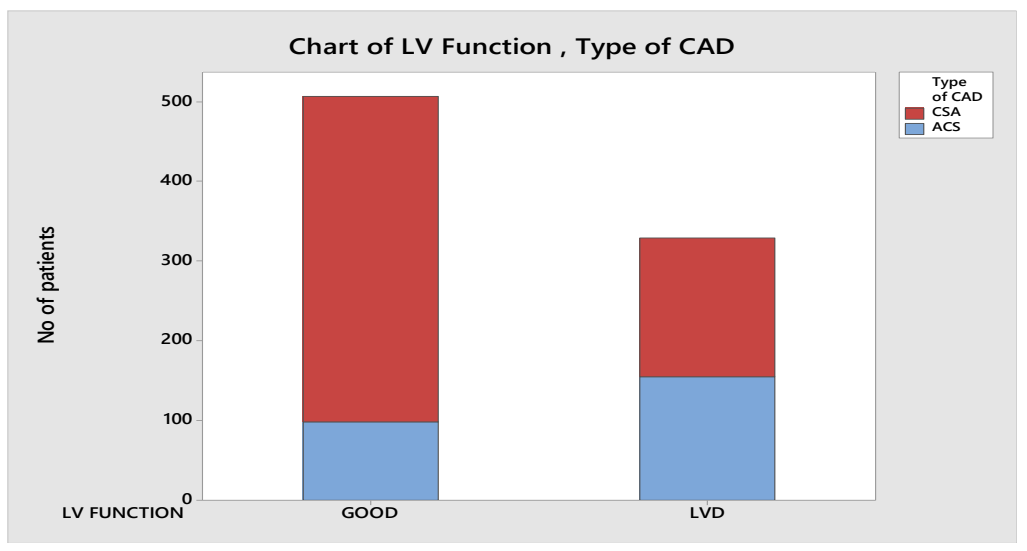

The baseline characteristics were listed in Tables 1, 2 \& 3 . 
Table 1: Baseline Clinical Parameters

\begin{tabular}{|l|c|c|c|c|c|}
\hline \multirow{2}{*}{ Variable } & \multicolumn{2}{|c|}{ LV Dysfunction } & \multicolumn{2}{c|}{ Good LV Function } & \multirow{2}{*}{ p value } \\
\cline { 2 - 5 } & Mean \pm St Dev. & Median & Mean \pm St Dev. & Median & 0.000 \\
\hline Systolic $(\mathrm{mmHg})$ & $142.15 \pm 26.88$ & 140 & $154.98 \pm 27.53$ & 150 & 0.68 \\
\hline Diastolic $(\mathrm{mmHg})$ & $76.58 \pm 52.69$ & 70 & $75.36 \pm 10.59$ & 75 & 0.63 \\
\hline Height $(\mathrm{cm})$ & $160.19 \pm 8.91$ & 160 & $159.38 \pm 8.53$ & 160 & 0.23 \\
\hline Weight $(\mathrm{kg})$ & $62.54 \pm 10.49$ & 61 & $64.68 \pm 11.86$ & 63 & 0.012 \\
\hline BMI $\left(\mathrm{kg} / \mathrm{m}^{2}\right)$ & $24.03 \pm 1.39$ & 23.88 & $25.15 \pm 1.79$ & 24.61 & 0.000 \\
\hline
\end{tabular}

Table 2: Baseline Lab Parameters

\begin{tabular}{|l|c|c|c|c|c|}
\hline \multirow{2}{*}{ Variable } & \multicolumn{2}{l|}{ LV Dysfunction } & \multicolumn{2}{l|}{ Good LV Function } & $p$ \\
\cline { 2 - 6 } & Mean \pm St Dev. & Median & Mean \pm St Dev. & Median & value \\
\hline $\begin{array}{l}\text { Leucocyte Count } \\
\text { (cells/cu.mm) }\end{array}$ & & & & \\
\hline Haemoglobin(g/dl) & $12.93 \pm 1.81$ & 12.9 & $8422.2 \pm 1858.1$ & 8700 & 0.16 \\
\hline platelet count (lakh/mm3) & $2.23 \pm 0.84$ & 1.9 & $12.76 \pm 1.56$ & 12.9 & 0.14 \\
\hline PCV $(\%)$ & $34.23 \pm 5.45$ & 34 & $33.95 \pm 5.61$ & 34 & 0.59 \\
\hline $\mathrm{Na}(\mathrm{mmol} / \mathrm{L})$ & $136.53 \pm 9.81$ & 136 & $1.05 \pm 0.38$ & 1 & 0.2 \\
\hline $\mathrm{K}+(\mathrm{mmol} / \mathrm{L})$ & $3.96 \pm 0.766$ & 4 & $137.44 \pm 6.54$ & 136 & 0.02 \\
\hline RBS $(\mathrm{mg} / \mathrm{dl})$ & $113.27 \pm 25.59$ & 106 & $4.09 \pm 0.66$ & 4.2 & 0.12 \\
\hline e GFR (ml/min/1.73m2) & $73.49 \pm 28.32$ & 69.9 & $117.31 \pm 25.52$ & 112 & 0.004 \\
\hline
\end{tabular}

Table 3: Baseline Lipid profile

\begin{tabular}{|l|c|c|c|c|c|}
\hline \multirow{2}{*}{ Variable } & \multicolumn{2}{|c|}{ LV Dysfunction } & \multicolumn{2}{c|}{ Good LV Function } & \multirow{2}{*}{} \\
\cline { 2 - 5 } & Mean \pm St. Dev. & Median & Mean \pm St Dev. & Median & p value \\
\hline Total cholesterol $(\mathrm{mg} / \mathrm{dl})$ & $141.6 \pm 33.31$ & 140 & $120.42 \pm 37.49$ & 118 & 0.57 \\
\hline HDL $(\mathrm{mg} / \mathrm{dl})$ & $32.56 \pm 12.54$ & 32 & $40.04 \pm 11.85$ & 38 & 0.004 \\
\hline LDL $(\mathrm{mg} / \mathrm{dl})$ & $57.88 \pm 27.02$ & 51.5 & $53.81 \pm 26.93$ & 49 & 0.26 \\
\hline VLDL $(\mathrm{mg} / \mathrm{dl})$ & $34.91 \pm 17.58$ & 29 & $26.93 \pm 15.12$ & 22 & 0.56 \\
\hline Triglycerides $(\mathrm{mg} / \mathrm{dl})$ & $132.56 \pm 39.47$ & 134.5 & $123.46 \pm 63.25$ & 110 & 0.25 \\
\hline
\end{tabular}

There was a significant increase in HDL and LDL cholesterol at 1 year compared to baseline $(\mathrm{p}=0.000 \& \mathrm{p}=0.01$ respectively) in patients with LV dysfunction. (Table. 4)

Table 4: Change in lipid parameters from basal to one year in LV Dysfunction Patients

\begin{tabular}{|l|c|c|c|}
\hline \multirow{2}{*}{ Variable } & Basal & One year & \multirow{2}{*}{ p Value } \\
\cline { 2 - 3 } & Mean \pm St Dev. & Mean \pm St Dev. & 0.2 \\
\hline Total Cholesterol $(\mathrm{mg} / \mathrm{dl})$ & $141.6 \pm 33.31$ & $136.4 \pm 69.09$ & 0.000 \\
\hline HDL $(\mathrm{mg} / \mathrm{dl})$ & $32.56 \pm 12.54$ & $38.77 \pm 10.63$ & 0.01 \\
\hline LDL $(\mathrm{mg} / \mathrm{dl})$ & $57.88 \pm 27.02$ & $63.96 \pm 32.67$ & 0.01 \\
\hline VLDL $(\mathrm{mg} / \mathrm{dl})$ & $34.91 \pm 17.58$ & $32.33 \pm 24.40$ & 0.3 \\
\hline Triglycerides $(\mathrm{mg} / \mathrm{dl})$ & $132.56 \pm 39.47$ & $136.59 \pm 56.01$ & \\
\hline
\end{tabular}


Multivessel PCI was done in 79 (24\%) patients with LVD and $110(21.7 \%)$ patients with GLV ( $\mathrm{p}=0.4)$. Predilatation was done in $210(25 \%)$ patients with LV dysfunction and 279(33\%) patients with good LV function (Fig.4).

Fig.4: Predilatation before PCI

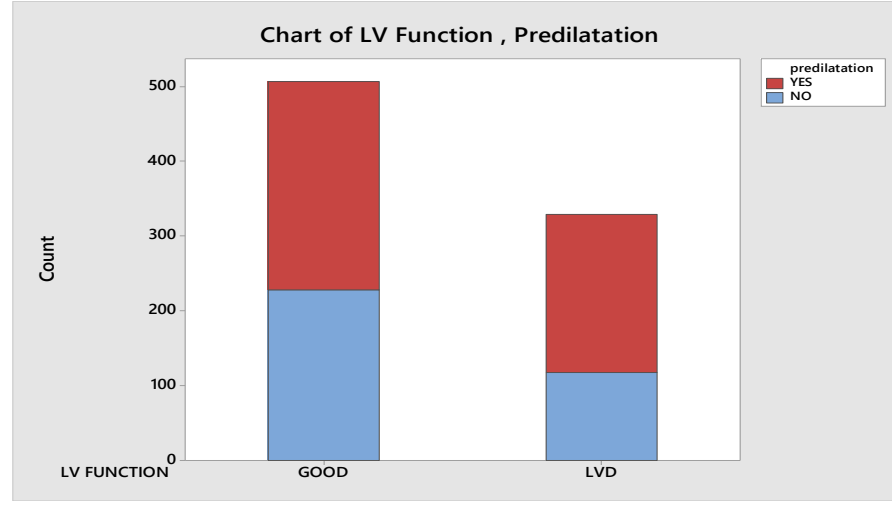

Stent thrombosis occurred in 1 patient with LV dysfunction $(\mathrm{p}=0.317)$. PCI was performed through radial approach in $300(36 \%)$ patients with $\mathrm{LV}$ dysfunction and 472(56\%) patients with good LV function.GP IIb/IIIa inhibitor was used in 30(3.6\%) patients with LV dysfunction and 31(3.7\%) patients with good LV function. Though patients with LV dysfunction are at more risk of adverse events, the requirement of GP IIb/IIIa inhibitors was equal between the two groups. Previous PCI was performed in 64(7.6\%) patients with LV dysfunction and $83(10 \%)$ patients with good LV function. Predilatation was more frequently performed in male patients with CSA in both the groups (Fig 5).

Figure.5: Comparison of predilatation with respect to sex, type of CAD in both groups

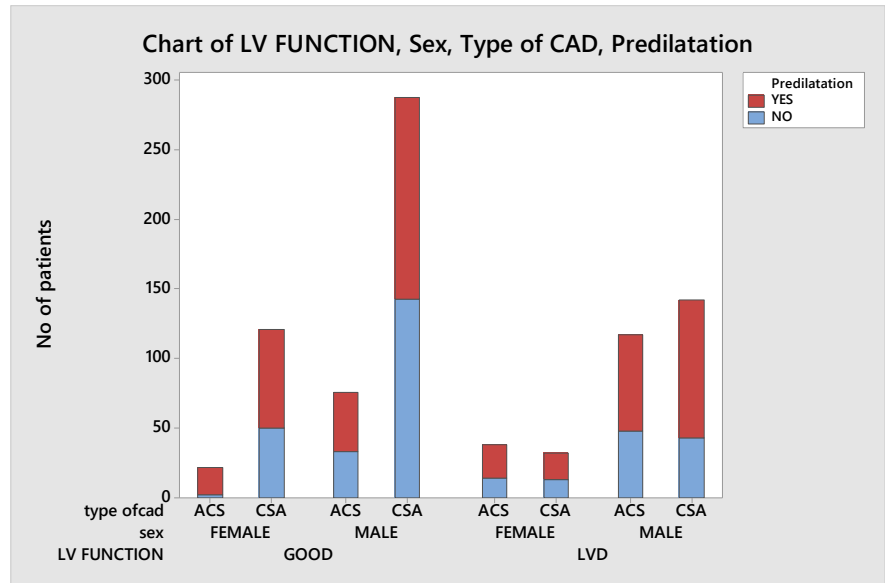

Major adverse cardiovascular and cerebrovascular events (MACCE) occurred in $3(1.87 \%)$ patients with mild ( 2 patients had nonfatal MI, 1 was hospitalized with heart failure), 5(5.6\%) patients with moderate (cardiovascular death occurred in 2 patients, 1 patient had nonfatal MI, 2 patients were hospitalized with heart failure), 6(7.5\%) patients with severe LVD (cardiovascular death occurred in 3 patients, 1 had nonfatal MI, 2 patients were hospitalized with heart failure) during the follow up of 1 year. There was no difference in outcomes between the LVD and GLV function group at one year $(p=0.2)$, but when a subgroup analysis was made among patients with LV dysfunction there was a significant occurrence of MACCE in patients with severe LV dysfunction when compared with mild LVD ( $\mathrm{z}=1.95, \mathrm{p}=0.051)$ by binary logistic regression. When chi square testing was done for the severity of LVD and events there was tendency for more clinical events in severe LVD group ( $\mathrm{p}=0.073$ ) compared to mild LV dysfunction.

\section{DISCUSSION:}

In the present study, we observed no significant difference between the occurrence of MACCE in patients with LV dysfunction and without LV dysfunction who underwent PCI.

Previous reports have suggested that impaired LV function predicts mortality $[1,3,4,7,8,12]$ and MACE outcomes [1,7] following PCI, although many were limited to only patients undergoing PCI in the elective setting $[1,8,11]$ and not specifically studying the differential impact of LV function on MACE or mortality across different PCI indications $[4,7,13]$.

But in our study, a subgroup analysis was performed and compared the occurrence of MACCE between mild, moderate and severe LV dysfunction patients. We found a significant occurrence of MACCE in patients with severe LV dysfunction when compared to mild LV dysfunction.

The association between LV function and adverse mortality may be accounted for by a number of possible mechanisms and is likely to be multifactorial. Patients with impaired LV function are less able to tolerate haemodynamic or ischaemic complications in the setting of a PCI due to reduced physiological reserve, which may explain the differential association particularly of severe LV dysfunction on mortality in different PCI 
settings with the highest independent risk observed in the STEMI cohort, where such haemodynamic and ischaemic complications are more prevalent and significant. In the longer term, patients with poor LV function are more likely to suffer progressive heart failure and arrhythmic deaths.

In keeping with other studies, we have observed that patients with reduced LV function undergoing PCI are older, more commonly diabetic, have a previous history of AMI and CABG $[1,3,4,7,8]$. Such adverse demographic features commonly found in patients with impaired LV function are known to contribute to unfavorable outcomes following PCI. Symptomatic heart failure and impaired LV function are known to be associated with adverse mortality outcomes in the medium and longer term [14, 15].

Previous studies have shown an association between stent thrombosis and LV function, for example, Sardi et al.[7] reported definite/probable stent thrombosis rates of $1.4 \%$ in patients undergoing PCI with good LV function and $6.0 \%$ in those patients with severe LV dysfunction $(\mathrm{EF}<25 \%)$ and this relationship persisted following adjustment for baseline co-variates. Acute coronary syndromes, particularly STEMI have been shown to independently increase the risk of early (acute and subacute) stent thrombosis 3.6-fold and delayed (late and very late) almost four-fold compared with elective PCI patients.[16] In our study stent thrombosis occurred in 1 patient with LV dysfunction( $\mathrm{p}=0.317)$.

Our analysis is of observational data and so cannot be used to infer a causal relationship between LV function and outcomes.

In conclusion, our current analysis of 836 patients who underwent PCI showed no significant occurrence of MACCE in patients with LV dysfunction compared to good LV function. But in a subgroup analysis, there was a tendency towards the occurrence of MACCE in patients with severe LV dysfunction compared to mild LV dysfunction.

\section{CONCLUSIONS:}

There is no significant difference between the occurrence of MACCE in patients with LV dysfunction and without LV dysfunction who underwent PCI. But when a subgroup analysis was done there was a significant occurrence of MACCE in patients with severe LV dysfunction $(p=0.05)$ when compared to mild LVD.

\section{REFERENCES:}

1. Keelan PC, Johnston JM, Koru Sengul T, Detre KM, Williams DO, Slater J, Block PC, Holmes DR Jr.; Dynamic Registry Investigators. Comparison of inhospital and one-year outcomes in patients with left ventricular ejection fractions $<$ or $=40 \%, 41 \%$ to $49 \%$, and $>$ or $=50 \%$ having percutaneous coronary revascularization. Am J Cardiol 2003; 91:1168-1172.

2. Grayson $A D$, Moore RK, Jackson $M$, Rathore S, Sastry S, Gray TP, Schofield I, Chauhan A, Ordoubadi FF, Prendergast B, Stables RH; North West Quality Improvement Programme in Cardiac Interventions. Multivariate prediction of major adverse cardiac events after 9914 percutaneous coronary interventions in the northwest of England. Heart 2006;92:658-663.

3. Daneault $B$, Généreux $P$, Kirtane AJ, Witzenbichler B, Guagliumi G, Paradis JM, Fahy MP, Mehran R, Stone GW. Comparison of Three-year outcomes after primary percutaneous coronary intervention in patients with left ventricular ejection fraction $<40 \%$ versus $\geq 40 \%$ (from the HORIZONS-AMI trial). Am J Cardiol 2013;111:12-20.

4. DeSilva K, Webb I, Sicard P, Lockie T, Pattinson S, Redwood S, Perera D. Does left ventricular function continue to influence mortality following contemporary percutaneous coronary intervention? Coron Artery Dis 2012;23:155-161.

5. Boden WE, O'Rourke RA, Teo KK, Hartigan PM, Maron DJ, Kostuk W, Knudtson M, Dada M, CaspersonP, Harris CL, Spertus JA, Shaw L, Chaitman BR, Mancini GB, Berman DS, Weintraub WS. Design and rationale of the Clinical Outcomes Utilizing Revascularization and Aggressive Drug Evaluation (COURAGE) trial Veterans Affairs Cooperative Studies Program No. 424. Am Heart J 2006;151:1173-1179.

6. Kapur A, Malik IS, Bagger JP, Anderson JR, Kooner JS, Thomas M, Punjabi P, Mayet J, Millane T, GoedickeJ, Jamrozik K, de Belder MA, Hall RJ, Beatt KJ. The Coronary Artery Revascularisation in Diabetes (CARDia) trial: background, aims, and design. Am Heart J 2005;149:13-19. 
7. Sardi GL, Gaglia MA Jr., Maluenda G, Torguson R, Laynez CarniceroA, BenDor I, Hauville C, Xue Z, Suddath WO, Kent KM, Satler LF, Pichard AD, Lindsay J, Waksman R. Outcome of percutaneous coronary intervention utilizing drug-eluting stents in patients with reduced left ventricular ejection fraction. Am J Cardiol 2012;109:344-351.

8. Wallace TW, Berger JS, Wang A, Velazquez EJ, Brown DL. Impact of left ventricular dysfunction on hospital mortality among patients undergoing elective percutaneous coronary intervention. Am J Cardiol 2009;103:355-360.

9. Peterson ED, Dai D, DeLong ER, Brennan JM, Singh M, Rao SV, Shaw RE, Roe MT, Ho KK, Klein LW, KroneRJ, Weintraub WS, Brindis RG, Rumsfeld JS, Spertus JA; NCDR Registry Participants. Contemporary mortality risk prediction for percutaneous coronary intervention: results from 588,398 procedures in the National Cardiovascular Data Registry. J Am CollCardiol2010;55:1923-1932.

10. Farooq V, Vergouwe Y, Räber L, Vranckx P, GarciaGarcia H, Diletti R, Kappetein AP, Morel MA, de VriesT, Swart M, Valgimigli M, Dawkins KD, Windecker S, Steyerberg EW, Serruys PW. Combined anatomical and clinical factors for the long-term risk stratification of patients undergoing percutaneous coronary intervention: the Logistic Clinical SYNTAX score. Eur Heart J 2012;33:3098-3104.

11. Briguori C, Aranzulla TC, Airoldi F, Cosgrave J, Tavano D, Michev I, Montorfano M, Carlino M, CastelliA,Sangiorgi MG, Colombo A. Stent implantation in patients with severe left ventricular systolic dysfunction. Int J Cardiol2009;135:376-384.

12. Holper EM, Blair J, Selzer F, Detre KM, Jacobs AK, Williams DO, Vlachos H, Wilensky RL, Coady P, Faxon DP; Percutaneous Transluminal Coronary Angioplasty Registry and Dynamic Registry Investigators. The impact of ejection fraction on outcomes after percutaneous coronary intervention in patients with congestive heart failure: an analysis of the National Heart, Lung, and Blood Institute Percutaneous Transluminal Coronary Angioplasty Registry and Dynamic Registry. Am Heart J 2006; 151:69-75.
13. BiondiZoccai G, Sheiban I, Moretti C, Palmerini T, Marzocchi A, Capodanno D, Tamburino C, MargheriM, Vecchi G, Sangiorgi G, Santarelli A, Bartorelli AL, Briguori C, Vignali L, PedeFd, Ramondo A, Medda M, deCarloM,Falsini G, Benassi A, Palmieri C, Filippone V, Sangiorgi D, Barlocco F, de Servi S. Appraising the impact of left ventricular ejection fraction on outcomes of percutaneous drug-eluting stenting for unprotected left main disease: insights from a multicenter registry of 975 patients. Clin Res Cardiol 2011;100:403-411.

14. McMurray JJ, Adamopoulos S, Anker SD, Auricchio A, Böhm M, Dickstein K, Falk V,FilippatosG, FonsecaC, GomezSanchez MA, JaarsmaT, Køber L, Lip GY, Maggioni AP, Parkhomenko A, Pieske BM, Popescu BA, RønnevikPK, Rutten FH, Schwitter J, Seferovic P, Stepinska J, Trindade PT, Voors AA, Zannad F, Zeiher A; ESC Committee for Practice Guidelines. ESC Guidelines for the diagnosis and treatment of acute and chronic heart failure 2012: The Task Force for the Diagnosis and Treatment of Acute and Chronic Heart Failure 2012 of the European Society of Cardiology. Developed in collaboration with the Heart Failure Association (HFA) of the ESC. Eur Heart J2012;33:17871847.

15. Yancy CW, Jessup M, Bozkurt B, Masoudi FA, Butler J, McBride PE, Casey DE Jr., McMurray JJ, DraznerMH, Mitchell JE, Fonarow GC, Peterson PN, Geraci SA, Horwich T, Januzzi JL, Johnson MR, Kasper EK, Levy WC, RiegelB, Sam F, Stevenson LW, Tang WH, Tsai EJ, Wilkoff BL; ACCF/AHA Task Force Members. 2013 ACCF/AHA Guideline for the Management of Heart Failure: A Report of the American College of Cardiology Foundation/American Heart Association Task Force on Practice Guidelines. J Am Coll Cardiol 2013; 1097:2114-2111.

16. Iqbal J, Sumaya W, Tatman V, Parviz Y, Morton AC, Grech ED, Campbell S, Storey RF, Gunn J. Incidence and predictors of stent thrombosis: a single-centre study of 5,833 consecutive patients undergoing coronary artery stenting. Euro Intervention 2013; 9:62-69. 